\title{
Endoscopic transnasal resection of anterior cranial fossa meningiomas
}

\author{
Enrico de Divitiis, M.D., Felice Esposito, M.D., Ph.D., Paolo Cappabianca, M.D., \\ Luigi M. Cavallo, M.D., Ph.D., Oreste de Divitis, M.D., and Isabella Esposito, M.D.
}

Department of Neurological Sciences, Division of Neurosurgery, Università degli Studi di Napoli Federico II, Via Sergio Pansini, Naples, Italy

Object. The extended transnasal approach, a recent surgical advancements for the ventral skull base, allows excellent midline access to and visibility of the anterior cranial fossa, which was previously thought to be approachable only via a transcranial route. The extended transnasal approach allows early decompression of the optic canals, obviates the need for brain retraction, and reduces neurovascular manipulation.

Methods. Between 2004 and 2007, 11 consecutive patients underwent transnasal resection of anterior cranial fossa meningiomas -4 olfactory groove (OGM) and 7 tuberculum sellae (TSM) meningiomas. Age at surgery, sex, symptoms, and imaging studies were reviewed. Tumor size and tumor extension were estimated, and the anteroposterior, vertical, and horizontal diameters were measred on MR images. Medical records, surgical complications, and outcomes of the patients were collected.

Results. A gross-total removal of the lesion was achieved in 10 patients $(91 \%)$, and in 1 patient with a TSM only a near-total $(>90 \%)$ resection was possible. Four patients with preoperative visual function defect had a complete recovery, whereas 3 patients experienced a transient worsening of vision, fully recovered within few days. In 3 patients ( 2 with TSMs and 1 with an OGM), a postoperative CSF leak occurred, requiring a endoscopic surgery for skull base defect repair. Another patient (a case involving a TSM) developed transient diabetes insipidus. The operative time ranged from 6 to 10 hours in the OGM group and from 4.5 to 9 hours in the TSM group. The mean duration of the hospital stay was 13.5 and 10 days in the OGM and TSM groups, respectively. Six patients ( 3 with OGMs and 3 with TSMs) required a blood transfusion. Surgery-related death occurred in 1 patient with TSM, in whom the tumor was successfully removed.

Conclusions. The technique offers a minimally invasive route to the midline anterior skull base, allowing the surgeon to avoid using brain retraction and reducing manipulation of the large vessels and optic apparatus; hastens postoperative recovery; and improves patient compliance. Further assessment and refinement are required, particularly because of the potential risk of CSF leakage. Other studies and longer follow-up periods are necessary to ascertain the benefits of the technique.(DOI: 10.3171/FOC.2008.25.12.E8)

\section{Key Words • endoscopy • extended transnasal approach • meningioma • olfactory groove • skull base - tuberculum sellae}

$\mathrm{T}$ HE extended transnasal approach can arguably be considered one of the last surgical advancements in ventral skull base procedures. It is a modification of the standard approach, traditionally targeting sellar lesions, allowing additional bone resection of the cranial base to reach several midline areas, from the frontal sinus (crista galli) to the craniovertebral junction. In contrast to transcranial surgical approaches $1,2,10,19,21,37-39,41-44,46,48$ to remove suprasellar masses, this technique offers a direct approach that allows excellent midline access to

\footnotetext{
Abbreviations used in this paper: $\mathrm{CSF}=$ cerebrospinal fluid; OGM = olfactory groove meningioma; TSM = tuberculum sellae meningioma.
}

and visibility of the anterior cranial fossa, obviating brain retraction and reducing neurovascular manipulation. ${ }^{11,15,17,23-25,30,31,33}$ Because of the strategic localization of the sphenoid sinus, the anterior cranial base can be exposed, passing through this air-filled cavity, depending upon its grade of pneumatization. Such a route, avoiding brain retraction, reduces the risks of brain injury and allows one to perform an early decompression of the optic canals, thus resulting in a better visual outcome. The use of the endoscope in such an approach has gained popularity because its side-viewing option provides a more panoramic view than the operating microscope. ${ }^{12}$ Thus, the transnasal approach, once used for access to sellar and/or intrasuprasellar subdiaphragmatic lesions only, 
E. de Divitiis et al.

TABLE 1: Summary of characteristics in patients with anterior cranial fossa meningiomas*

\begin{tabular}{|c|c|c|c|c|c|}
\hline $\begin{array}{l}\text { Case } \\
\text { No. }\end{array}$ & $\begin{array}{c}\text { Age (yrs), } \\
\text { Sex }\end{array}$ & $\begin{array}{c}\text { Tumor } \\
\text { Location }\end{array}$ & Tumor size (cm) & Preop Visual Function & Other Symptoms \\
\hline 1 & $65, F$ & $O G$ & $2.4 \times 2 \times 3$ & normal & headache \\
\hline 2 & $35, M$ & $O G$ & $4.8 \times 0.8 \times 6$ & rt amaurosis; It 1/60 & $\begin{array}{l}\text { Foster-Kennedy syndrome; } \\
\text { psychiatric disorders }\end{array}$ \\
\hline 3 & $44, \mathrm{~F}$ & $\mathrm{OG}$ & $3.5 \times 3.4 \times 3.8$ & normal & epilepsy; psychiatric disorders \\
\hline 4 & $53, F$ & $O G$ & $3 \times 2.8 \times 2.6$ & normal & bilat hyposmia \\
\hline 5 & $51, \mathrm{~F}$ & TS & $2.4 \times 2.7 \times 2.4$ & rt temporal hemianopia; VA: rt 1/30; It 2/10 & none \\
\hline 6 & $71, \mathrm{~F}$ & TS & $1.4 \times 1.8 \times 1.3$ & normal & headache \\
\hline 7 & $47, \mathrm{~F}$ & TS & $2.5 \times 2.4 \times 2.3$ & rt temporal hemianopia; VA: It $1 / 60$ & headache \\
\hline 8 & $47, M$ & TS & $2.7 \times 2.7 \times 2.1$ & bitemporal hemianopia; VA: rt 2/10 & none \\
\hline 9 & $58, M$ & TS & $3.2 \times 2.6 \times 2.9$ & bitemporal hemianopia; VA: rt 4/10; It: 2/10 & none \\
\hline 10 & $57, \mathrm{M}$ & TS & $1.8 \times 1.6 \times 1.9$ & VA: rt 6/10; It $7 / 10$ & none \\
\hline 11 & $80, \mathrm{~F}$ & TS & $2.8 \times 2.6 \times 3$ & $\begin{array}{l}\text { It temporal hemianopia; VA: rt amaurosis; } \\
\text { It } 1 / 10\end{array}$ & none \\
\hline
\end{tabular}

${ }^{*} \mathrm{OG}=$ olfactory groove; $\mathrm{TS}$ = tuberculum sella.

is used today, even more frequently, for lesions, among them meningiomas, located outside the sella. The aim of this study was to analyze clinical outcome in a series of patients harboring anterior cranial fossa meningiomas treated via the transnasal approach. The individual merits and weaknesses of this increasingly standardized technique are discussed.

\section{Methods}

Between 2004 and 2007, 11 consecutive patients underwent transnasal resection of anterior cranial fossa meningiomas (4 OGMs and 7 TSMs) at the Department of Neurosurgery of the University Federico II of Naples (Table 1). This approach was used after acquiring experience in more than 500 cases in which patients underwent a standard transsphenoidal procedure to reach sellar masses, particularly pituitary adenomas. Age at surgery, sex, symptoms, and imaging studies were reviewed. Tumor size and tumor extension were estimated, measuring the anteroposterior, vertical, and horizontal diameters on MR images. Medical records, surgical complications, and outcome of the patients were noted. On postoperative Day 4 the patients underwent an endoscopic check of the nasal fossa, after injection of a local anesthetic, to control the proper positioning of the graft material. All patients underwent a 3-month follow-up examination and contrastenhanced 1.5-T MR imaging in which we obtained highresolution and thin-section images of the area involved by the tumor. Written informed consent was obtained for all patients, and patients were informed that a craniotomy would be undertaken if difficulties were encountered. In no case was the surgery converted to a transcranial procedure.

The complaints that led to evaluation were visual loss, in cases of TSMs, or personality change and psychiatric symptoms, in patients with OGMs. Anosmia was present in all patients with symptomatic OGMs, but only in 1 case was it the symptom that led to diagnosis. In 1 case the tumor was asymptomatic and was detected on a CT scanning conducted for a minor traumatic brain injury.

\section{Surgical Procedure}

As previously described in detail elsewhere, ${ }^{13,14}$ the direct transnasal approach is performed using a rigid straight $0^{\circ}$ endoscope as the sole visualizing device, without the use of a nasal speculum. Angled endoscopes of $30-45^{\circ}$ are used to confirm the completeness of the resection, allowing visualization in all directions of the operative field. In contrast to the standard technique, in which the endoscope is attached to a holder that allows the surgeon to operate bimanually alone, in transnasal approach we prefer a collaborative surgery in which 2 surgeons work through both nostrils, with 2 or 3 instruments plus the endoscope, alternately held by 1 of the surgeons, since it needs to be continuously moved to look around corners during the entire procedure to gain the sense of depth. Kassam and his team from Pittsburgh ${ }^{27-29}$ provided the guidelines for performing extended endoscopic endonasal surgery for the management of skull base lesions and systematized such surgical strategies along the coronal and sagittal planes according to strict anatomical principles.

\section{Basic Module}

This first step of the surgical procedure can be considered the common denominator of all the extended approaches.

Different from the standard transsphenoidal approach, targeted for sellar lesions, this expanded approach requires some modifications aimed to increase the working space and the maneuverability of the instruments in the surgical corridor. The creation of such a wide corridor requires these steps: 1) middle turbinectomy on 1 side (the mucoperiosteum of the turbinate is kept for the reconstruction); 2) lateralization or removal (in case of the 


\section{Endoscopic transnasal resection}

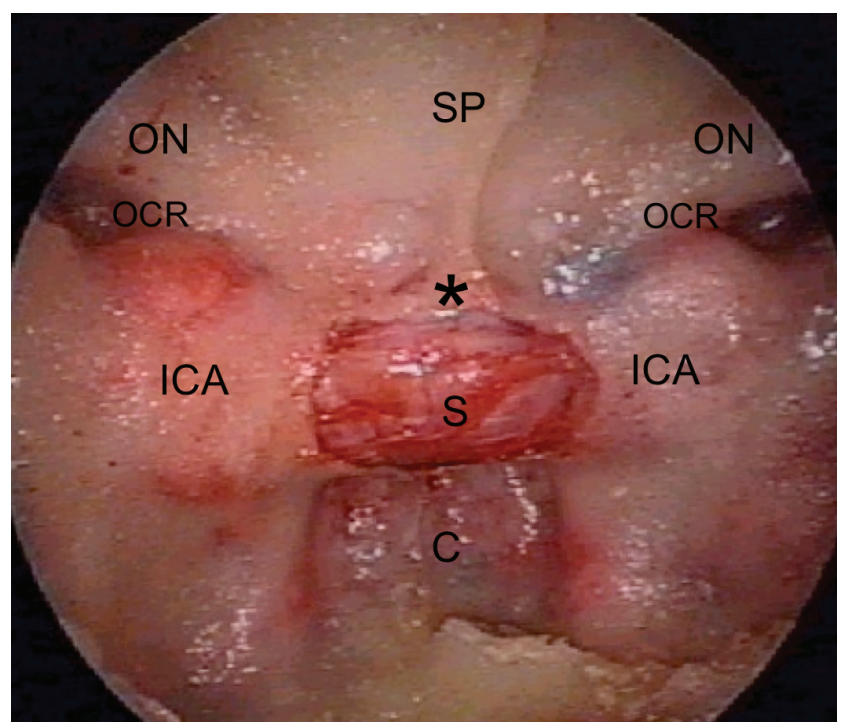

FIG. 1. Anatomical photograph showing the landmarks on the posterior wall of the sphenoid sinus. The asterisk indicates the tuberculum sellae. $\mathrm{C}=$ clivus; $\mathrm{ICA}=$ internal carotid artery; $\mathrm{OCR}=$ opticocarotid recess; $\mathrm{ON}=$ optic nerve; $\mathrm{S}=$ sella; $\mathrm{SP}=$ sphenoid planum.

transcribriform approach) of the contralateral turbinate; 3) removal of the posterior portion of the nasal septum; and 4) wider anterior sphenoidotomy (the sphenopalatine artery should be preserved, if use of a vascularized nasal mucosal flap is foreseen for the reconstruction or to avoid the complication of delayed epistaxis).

Once the sphenoid cavity is exposed, a series of osseous landmarks can be identified on the structure's posterior wall: the sellar prominence at the center, the planum sphenoidale above it, and the clival indentation below; lateral to the sella the prominences of the intracavernous carotid arteries and, more superiorly, the optic nerves; between them the opticocarotid recesses, molded by the pneumatization of the optic strut of the anterior clinoid processes (Fig. 1).

\section{Specific Modules}

Once a wider working space is achieved, to accommodate instruments' maneuvrability, 2 different approaches to the anterior cranial fossa are afforded due to the different locations in the anterior cranial fossa of OGMs and TSMs.

\section{Transtuberculum/Transplanum Approach}

A transtuberculum/transplanum approach ${ }^{7,8,13,28,47}$ approach is used for the removal of TSMs. Bone removal starts with the resection of the upper half of the sella to expose the superior intercavernous sinus.

The tuberculum sellae, freed from the medial aspect of both opticocarotid recesses and from the posterior part of the planum sphenoidale, is gently dissected from the dura mater and removed. The bone resection continues across the tuberculum toward the planum sphenoidale, thus affording access to the suprasellar cistern. A Kerrison rongeur is used to complete the removal of the bone from the planum up to reach the falciform ligament, and

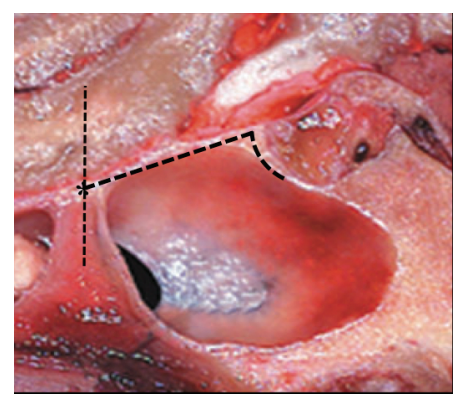

FIG. 2. Sagittal anatomical photograph. The dotted line shows the limits of bone resection for the approach to TSMs, the asterisk indicates the posterior ethmoidal artery, and the vertical dotted line shows the anterior limit of the approach.

the both posterior ethmoidal arteries. These landmarks usually represent the anterior limit of the osteodural opening.

The boundaries of the approach are as follows: anteriorly, the planum sphenoidale until the posterior ethmoidal arteries; posteriorly, the upper half of the sella; and laterally, the medial aspect of the opticocarotid recesses (Fig. 2).

\section{Transcribriform Approach}

The transcribriform approach ${ }^{7,8,28,47}$ is targeted to remove OGMs. Once the anterior sphenoidotomy is performed, the bone resection extends the previous approach more rostrally, passing through the anterior and posterior ethmoid, to the posterior wall of the frontal sinuses. The bulla ethmoidalis and the ethmoid cells are open to expose the lamina papyracea laterally, the floor of the anterior cranial base superiorly, and the superior half of the posterior nasal septum on the midline. This latter structure is removed to allow a wide exposure of the contralateral skull base; such an area is divided into 2 parts by the lamina perpendicularis of the ethmoid. Finally, the superior portion of the lamina papyracea (medial orbital wall) is removed, and both the medial aspects of the orbits and the anterior and posterior ethmoidal arteries are exposed and coagulated to devascularize the tumor. Care must be taken to avoid traction on and/or disruption of these arteries, close to the orbital foramen, where they exit the orbits, especially in case of a pneumatized ethmoid, where these arteries are dehiscent, because their intraorbital retraction can cause hematoma or proptosis.

The boundaries of the approach are as follows: anteriorly, the back wall of the frontal sinuses; laterally, the medial walls of the 2 orbits; and posteriorly, the anterior part of the planum sphenoidale at the level of the posterior ethmoidal arteries. These arteries mark the limit between the planum sphenoidale and the lamina cribra (Fig. 3).

During these 2 approaches the bone resection can be extended, if required by the particular attachment of the tumor, only along the sagittal axis, because a further lateral extension is restricted by anatomical structures, such as the opticocarotid recesses for TSMs and the medial walls of the orbits for OGMs. Some cases of laterally located OGMs may require a unilateral osteodural opening. 


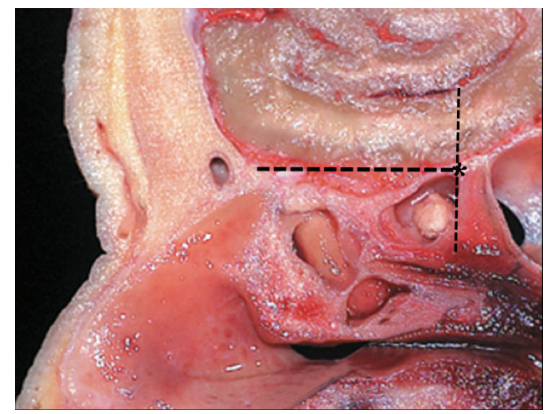

FIG. 3. Sagittal anatomical photograph. The dotted line shows the limits of bone resection for the approach to olfactory groove meningiomas, the asterisk indicates the posterior ethmoidal artery, and the vertical dotted line shows the posterior limit of the approach.

Once the bone resection, tailored to the specific tumor anatomy, has been accomplished, the base of the tumor is approached for devascularization. The tumor is debulked and the surrounding arachnoid is dissected away from the tumor capsule. If bleeding occurs, visibile sources are coagulated or gently packed with a hemostat and cottonoid patties. Once the tumor has been freed from any adherence, the tumor capsule can be gently teased from surrounding structures and removed piecemeal or en bloc. Once the removal is complete, the operative field is inspected and irrigated, and the local anatomy of the region should be visibile. A film of fibrin glue is injected on the operative field to protect the intradural structures and any packing that is left, to avoid the risk of overpacking, and to allow better interpretation of the postoperative MR imaging studies.

\section{Surgical Closure}

At the conclusion of the procedure, reconstruction of the osteodural defect should be tailored in accordance with the shape of the osteodural opening, with the goal being a watertight closure. The anterior cranial floor is closed in multilayered fashion with collagen sponge matrix (Duragen, Integra LifeSciences Corp., or Tissufleece, Baxter Bioscience), dural substitute (Tutoplast, Tutogen Medical, $\mathrm{GmbH}$ ), resorbable solid material (Lactosorb, Lorenz Surgical), and fibrinogen sealant (Tisseel, Baxter BioSciences). We used a Valsalva maneuver to test for further leakage; if the packing did not stop all visibile leakage, the sphenoid sinus was obliterated with Oxycel and reinforced by inflating a Foley catheter-inserted through 1 nostril-to hold the reconstruction. The preparation of a vascularized pedunculated mucosal flap, obtained from the nasal septum to facilitate the healing of the graft, represents the most recent novel reconstruction technique and was used in the last 3 cases $^{22}$. Finally, no packing is left in the nose.

\section{Results}

The results obtained in our 11 patients with anterior cranial base meningiomas are summarized in Table 2.

Over a 28 -month period, 11 patients (4 males and 7 females; mean age 56.1 years, range $44-80$ years) underwent an extended endoscopic transsphenoidal approach for the treatment of TSMs (7 cases) and OGMs (4 cases). A gross-total removal of the lesion was achieved in 10 patients (91\%), whereas in 1 case of TSM only a near-total

TABLE 2: Results obtained in patients with anterior cranial fossa meningiomas*

\begin{tabular}{|c|c|c|c|c|c|c|c|c|c|c|}
\hline $\begin{array}{l}\text { Case } \\
\text { No. }\end{array}$ & $\begin{array}{l}\text { Tumor } \\
\text { Site }\end{array}$ & $\begin{array}{l}\text { Histopatholog- } \\
\text { ical Finding } \\
\text { (WHO grade) }\end{array}$ & $\begin{array}{c}\text { Tumor } \\
\text { Removal }\end{array}$ & $\begin{array}{l}\text { Blood } \\
\text { Trans- } \\
\text { fusion }\end{array}$ & $\begin{array}{l}\text { Op Time } \\
\text { (hrs) }\end{array}$ & $\begin{array}{l}\text { Lumbar } \\
\text { Drain }\end{array}$ & $\begin{array}{l}\text { Postop } \\
\text { Stay } \\
\text { (days) }\end{array}$ & $\begin{array}{l}\text { Postop Visual } \\
\text { Function }\end{array}$ & Complications & $\begin{array}{c}\text { FU } \\
\text { (mos) }\end{array}$ \\
\hline 1 & $O G$ & $\begin{array}{l}\text { psammoma- } \\
\text { tous (I) }\end{array}$ & total & no & 6 & no & 7 & normal & none & 12 \\
\hline 2 & $O G$ & transitional (I) & total & yes & $10+11 \dagger$ & no & 32 & unchanged & CSF leak & 8 \\
\hline 3 & OG & syncytial (I) & total & yes & 10 & no & 10 & normal & none & 10 \\
\hline 4 & $O G$ & transitional (I) & total & yes & 8 & no & 5 & normal & none & 9 \\
\hline 5 & TS & fibroblastic (I) & total & no & 4.5 & no & 10 & improved & none & 51 \\
\hline 6 & TS & transitional (I) & total & no & 6 & no & 10 & normal & none & 32 \\
\hline 7 & TS & atypical (II) & total & no & 7 & no & 7 & $\begin{array}{l}\text { improved in rt; } \\
\text { worsened It }\end{array}$ & transient DI & 25 \\
\hline 8 & TS & transitional (I) & total & yes & 9 & no & 5 & improved & none & 24 \\
\hline 9 & TS & atypical (II) & total & yes & 6 & noß & 21 & unchanged & $\begin{array}{l}\text { CSF leak, intraven- } \\
\text { tricular hemorrhage, } \\
\text { death }\end{array}$ & $\begin{array}{c}0.75 \\
\text { (dead) }\end{array}$ \\
\hline 10 & TS & transitional (I) & $\begin{array}{l}\text { near total } \\
(>90 \%)\end{array}$ & no & 7 & noß & 9 & improved & CSF leak & 20 \\
\hline 11 & TS & fibroblastic (I) & total & yes & 8 & no & 8 & unchanged & none & 15 \\
\hline
\end{tabular}




\section{Endoscopic transnasal resection}

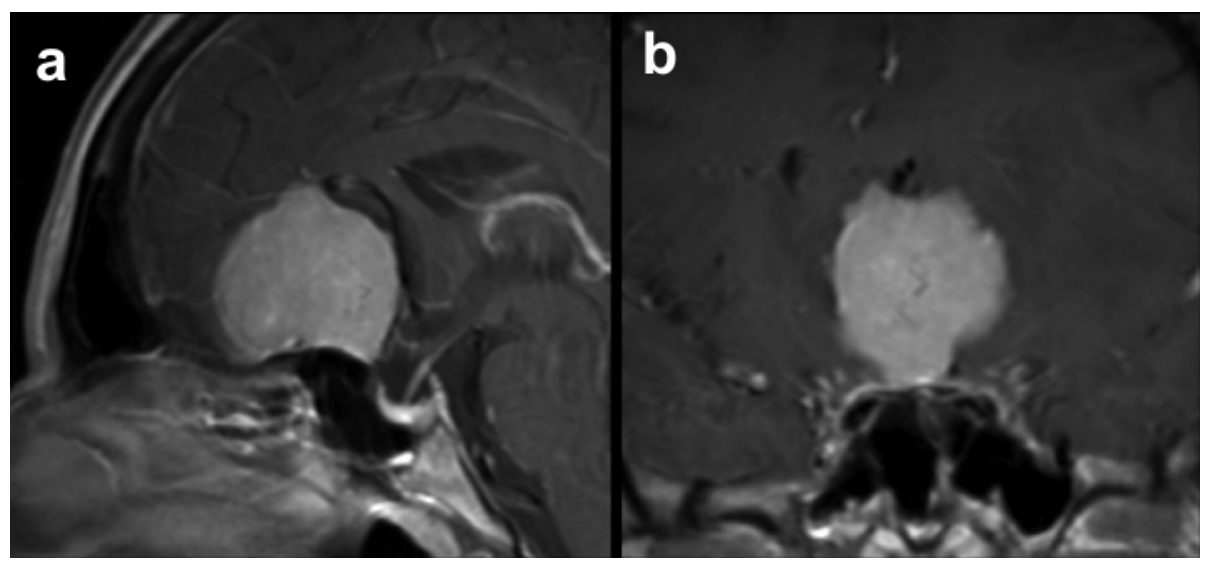

FIG. 4. Preoperative contrast-enhanced sagittal (a) and coronal (b) MR images showing a case of OGM.

removal ( $>90 \%)$ was possible because a portion of the tumor extended inside the superolateral part of the right optic canal. On postoperative evaluation, 4 patients with preoperative visual dysfunction had experienced a complete recovery, whereas 3 patients experienced a transient worsening of vision, which was fully recovered within a few days. Three cases (2 involving a TSM and 1 an OGM) had postoperative CSF leaks, requiring successful endoscopic redo surgery for skull base defect repair. Another patient (with a TSM) developed transient diabetes insipidus requiring hormonal replacement therapy, which resolved within few weeks. All patients resumed preoperative levels of social and professional activity. The operative time ranged from 6 to 10 hours in the OGM group (in 1 case of a very large OGM a 2-staged operation was needed) and from 4.5 to 9 hours in the TSM group. The mean duration of the hospital stay was 13.5 and 10 days in the OGM and TSM groups, respectively. Six patients ( 3 with OGMs and 3 with TSMs) required blood transfusion. Surgery-related death occurred in 1 patient treated for a TSM, in whom the tumor had been successfully removed; he died 3 weeks later of an unexpected massive intraventricular hemorrhage. ${ }^{14}$

The follow-up periods ranged from 8 to 12 months in the OGM group and from 3 weeks to 51 months in the TSM group (1 patient with a TSM died 3 weeks after surgery).

\section{Discussion}

The goal of the transnasal endoscopic approach for anterior cranial fossa meningiomas is removal of as much of the lesion as possible, avoiding brain retraction, and minimizing neurovascular structure manipulation. When considering this novel approach, the outcomes and complication prevention should be in line with those of a transcranial approach. Meningiomas extending into the suprasellar area pose a separate set of challenges and concerns from a clinical and a surgical point of view. These include: 1) the different tumor size (OGMs are larger than TSMs); 2) different surgical approaches; and 3) different structures involved in the tumor dissection. The tumorrelated conditions that can represent potential restrictions include: 1) tumor size; 2) eccentric shape; 3) main vessel encasement; 4) tumor extension within the optic canal(s) and/or the cavernous sinus; and 5) large lateral dural attachment. Although the sagittal axis of the tumor does not represent a problem, because the bone resection can be extended along this axis without any restrictions, the horizontal axis poses a critical problem. Indeed, during the transtubercular approach, bone resection beyond the medial aspect of the opticocarotid recesses risks injury to the optic nerves and/or carotid arteries, whereas during a transcribriform approach the attempts to go beyond the medial orbital walls poses the risk of entering the orbits (Fig. 4).

Since only selected lesions can be considered suitable for a low-route approach, preoperative neuroradiological workup, providing vital information related to the features of the tumor and relative distances between the surgical landmarks ${ }^{16}$ has significant impact on the choice of the best surgical approach. In most patients complete removal can be accomplished with a low morbidity rate and good recovery of neurological function. However, in some patients in whom total removal carries risks (due to age, general medical conditions, and so on), some portion of the tumor may be left, leaving the remaining portion for control with radiosurgery, or a wait-and-see policy may be adopted, and the patient should be followed up with periodic images.

Several authors have previously described their experience with the transnasal approach for suprasellar meningiomas. ${ }^{11,15,17,23-25,30,31,33}$ In a recent publication the role of the transnasal as compared with the transcranial approach has been reviewed. ${ }^{15,20,32}$ The discussion of which approach is appropriate often hinges on the features of a single tumor and its relationship with the main neurovascular structures. The transnasal technique may also be used in cases in which these structures are involved, ${ }^{47}$ even though aggressive surgery may not lead to optimal outcomes.

\section{Tumor Removal}

The grade of tumor excision had significant correlations with the tumor size and shape, vascular encasement and optic canal extension, and base of attachment. The 


\section{E. de Divitiis et al.}

grade has been estimated based on the surgeon's intraoperative impression and neuroimaging criteria. Total tumor removal was achieved in 10 of our patients, while in one case of a TSM only a near-total removal was accomplished because a tongue of tumor extended inside the superolateral part of the optic canal. In 1 case of a very large OGM, total removal of the lesion was achieved in a 2-stage operation (the first lasted 12 hours and the second, 1 week later, lasted 13 hours). Our short-term results are similar to those reported by other authors with experience in the extended transsphenoidal technique. In fact, the problem of recurrence remains a challenge and cannot be adequately assessed without longer follow-up. Even in presumably cured patients, recurrence can recur after many years.

A review of operative transcranial series indicates that the percentage of patients having a complete excision has varied from 50 to $100 \%$ for OGMs and from 76 to $100 \%$ for TSMs. The most commonly cited reason for incomplete resection was encasement of the main vessels.

\section{Visual Outcome}

Because the major clinical presentation symptom is visual change, improvement and/or preservation of visual function takes priority in this surgery. All patients with TSMs in this series presented with visual deficits, whereas no patients harboring OGMs presented with visual changes. Visual function, investigated before and after surgery, improved in 5 and remained unchanged in 2 of 7 patients with TSMs, whereas no patients had postoperative visual worsening, thus confirming the results reported in the pertinent literature, in studies with tabulated cases. ${ }^{11,15,17,23-25,30,31,33}$ A review of the most representative transcranial series has shown a high postoperative rate of improved visual function $(60 \%)$ and unchanged visual function (30\%); conversely, an overall $13 \%$ had a postoperative visual worsening. 1,2,10,19,21,37-39,41-46,48 Benjamin and Russell ${ }^{3}$ reported visual worsening in $19 \%$ of their patients. Goel et al. ${ }^{21}$ described a severe visual deficit in 14 of 70 TSMs. Nakamura et al. ${ }^{38}$ reported visual impairment in $9.7 \%$ of patients with tumors smaller than $30 \mathrm{~mm}$ and $16 \%$ with tumors larger than $30 \mathrm{~mm}$. According to Fahlbusch and Schott ${ }^{19}$ and Raco et al., ${ }^{44}$ the size of the tumor is critical and influences the visual outcome; patients with tumors smaller than $30 \mathrm{~mm}$ had a better visual outcome compared as those with tumors larger than $30 \mathrm{~mm}$.

This higher rate of postoperative visual loss after a transcranial approach occurs despite the more or less wide opening of the optic canal and the dural sheet, which is strongly proposed to allow the optic nerve to better tolerate the surgical manipulations, done intra- or extradurally, early or late..$^{35,40}$ Visual deterioration can habitually be due to direct surgical trauma and/or compromise of vascular supply to the optic apparatus, sometimes mistaken for tumor feeders. Compared with transcranial series, the lower rate of postoperative visual loss following a transnasal approach is due to the selection of more favorable patient population and the reduced manipulation of the optic apparatus, which can be habitually compressed, stretched, and kinked by the tumor at the falciform liga- ment. The transnasal approach allows early exposure of the tumor base, its devascularization and debulking, and provides a direct exposure of the inferomedial surface of the optic canals, affording a prompt decompression of the visual apparatus. Given the peculiar anatomical relationships between the tumor and the surrounding neurovascular structures, the tumor, growing in the subdural space, remains outside the arachnoid, so this membrane and the flow of the CSF in the basal cistern form a protective and separable interface between the meningioma and these structures, acting as a barrier to pial invasion and facilitating a safer extra-arachnoidal resection.

Although tumor removal, restoration of visual function, and status of CSF leakage are the primary outcomes that determine success of this technique, secondary outcomes are important determinants of the quality of surgery: duration of hospital stay, operative times, and surgery-related morbidity and mortality rates. The duration of hospital stay, operative time, and blood loss were lower in the transnasal group than in the transcranial group, ${ }^{32}$ whereas operative times in our hands have been significantly longer. Indeed, this could be due to the fact that 1 patient with an OGM in our series underwent a 2-stage operation that totaled 21 hours.

It has been demonstrated that there is a reduction in the postoperative morbidity rate, particularly hemorrhagic complications, brain parenchyma injury, and seizure in patients in whom the transnasal approach is used, although the rate of postoperative CSF leakage is higher in this group. ${ }^{15}$

Postoperative olfaction did not return to normal in any of the patients with olfactory loss before surgery. In cases involving smaller tumors, the olfactory nerves are displaced laterally on the surface of the tumor, and preservation of at least 1 of these nerves is possible. In cases involving larger tumors, however, the nerves are so adherent to the tumor and spread out on the capsule of the meningioma that they cannot be spared either during transcranial or transnasal surgery.

\section{Reconstruction}

Concerning the CSF leak, the operative conditions encountered during an extended approach are more complex than those in a standard procedure. Reconstruction of the osteodural defect represents a crucial point and its failure can compromise the result of the surgical procedure. Even after radical transcranial surgery in OGMs, CSF leakage remains an important issue. ${ }^{36}$ In fact, such meningiomas can involve the skull base in its weakest areas of the cribriform plate. In such cases, the nasal portion of the tumor can be removed from above and its excision can be verified using an angled mirror. ${ }^{39}$ For prevention of a CSF leak, however, a vascularized pericranial flap is usually used as a barrier to separate the intradural compartment and the paranasal sinuses. This technique is fairly easy during a subfrontal approach, but it is more technically demanding during the frequently used pterional or frontolateral routes, and thus a free pericranial flap is used in these circumstances.

Indeed, because of larger bone and dural openings, conspicuous leaks are present; moreover, brain pulsation 


\section{Endoscopic transnasal resection}

exerts high pressure over the cranial base defect. Thus the broad communication between the intradural space and nasal fossas increases the risk of infection. Nevertheless, meningitis should not be expected in cases of an effective watertight closure of an osteodural defect. Different techniques and materials have been successfully used for this purpose over the years, ${ }^{4-6,9,18,26,34}$ a vascularized mucosal flap from the nasal septum, recently proposed, ${ }^{9,22}$ seems to be effective because it facilitates the healing process.

Even though the development of a CSF leak after an extended transnasal approach is thought of as the Achilles heel of such techniques, one must remember that there is no direct correspondence between the rate of postoperative CSF leakage and death. In fact, all cases of meningitis have been successfully cured with antibiotics and all cases of CSF leakage have been successfully treated after reoperation.

\section{Conclusions}

Modifications of the traditional transsphenoidal approach, facilitated by the use of the endoscope as the sole visualizing device, have provided access to anterior cranial fossa meningiomas, previously thought to be resectable only via the transcranial route. The technique offers a minimally invasive route to the midline anterior skull base, avoids brain retraction, and reduces manipulation of main vessels and the optic apparatus. It also affords quicker postoperative recovery and better patient compliance. However, further assessment and refinement are required, particularly because of the potential risk of a CSF leak.

Further studies and longer follow-up are required to determine the benefits of the technique.

\section{References}

1. Al-Mefty O, Smith R: Tuberculum sellae meningiomas, in AlMefty O (ed): Meningiomas. New-York: Raven Press, 1991, pp 395-411

2. Bassiouni H, Asgari S, Stolke D: Tuberculum sellae meningiomas: functional outcome in a consecutive series treated microsurgically. Surg Neurol 66:37-45, 2006

3. Benjamin V, Russell SM: The microsurgical nuances of resecting tuberculum sellae meningiomas. Neurosurgery 56:411-417, 2005

4. Cappabianca P, Cavallo LM, Esposito F, Valente V, de Divitiis E: Sellar repair in endoscopic endonasal transsphenoidal surgery: results of 170 cases. Neurosurgery 51:1365-1372, 2002

5. Cappabianca P, Cavallo LM, Valente V, Romano I, D'Enza AI, Esposito F, et al: Sellar repair with fibrin sealant and collagen fleece after endoscopic endonasal transsphenoidal surgery. Surg Neurol 62:227-233, 2004

6. Castelnuovo P, Locatelli D, Mauri S: Extended endoscopic approaches to the skull base. Anterior cranial base CSF leaks, in de Divitiis E, Cappabianca P (eds): Endoscopic Endonasal Transsphenoidal Surgery. New York: Springer, 2003, pp 137-158

7. Cavallo LM, de Divitiis O, Aydin S, Messina A, Esposito F, Iaconetta G, et al: Extended endoscopic endonasal transsphenoidal approach to the suprasellar area: anatomic considerations - part 1. Neurosurgery 61(3 Suppl):24-34, 2007

8. Cavallo LM, Messina A, Cappabianca P, Esposito F, de Div- itiis E, Gardner P, et al: Endoscopic endonasal surgery of the midline skull base: anatomical study and clinical considerations. Neurosurg Focus 19(1):E2, 2005

9. Cavallo LM, Messina A, Esposito F, de Divitiis O, Dal Fabbro M, de Divitiis E, et al: Skull base reconstruction in the extended endoscopic transsphenoidal approach for suprasellar lesions. J Neurosurg 107:713-720, 2007

10. Ciric I, Rosenblatt S: Suprasellar meningiomas. Neurosurgery 49:1372-1377, 2001

11. Couldwell WT, Weiss MH, Rabb C, Liu JK, Apfelbaum RI, Fukushima T: Variations on the standard transsphenoidal approach to the sellar region, with emphasis on the extended approaches and parasellar approaches: surgical experience in 105 cases. Neurosurgery 55:539-550, 2004

12. de Divitiis E: Endoscopic transsphenoidal surgery: stone-inthe-pond effect. Neurosurgery 59:512-520, 2006

13. de Divitiis E, Cavallo LM, Cappabianca P, Esposito F: Extended endoscopic endonasal transsphenoidal approach for the removal of suprasellar tumors: part 2. Neurosurgery 60:46-59, 2007

14. de Divitiis E, Cavallo LM, Esposito F, Stella L, Messina A: Extended endoscopic transsphenoidal approach for tuberculum sellae meningiomas: endoneurosurgical nuances. Neuosurgery 61:229-238, 2007

15. de Divitiis E, Esposito F, Cappabianca P, Cavallo LM, de Divitiis O: Tuberculum sellae meningiomas: high route or low route? A series of 51 consecutive cases. Neurosurgery 62:556-563, 2008

16. de Notaris M, Esposito I, Cavallo LM, Burgaya AC, Galino AP, Esposito F, et al: Endoscopic endonasal approach to the ethmoidal planum: anatomic study. Neurosurg Rev 31:309317,2008

17. Dusick JR, Esposito F, Kelly DF, Cohan P, DeSalles A, Becker DP, et al: The extended direct endonasal transsphenoidal approach for nonadenomatous suprasellar tumors. J Neurosurg 102:832-841, 2005

18. Esposito F, Dusick JR, Fatemi N, Kelly DF: Graded repair of cranial base defects and cerebrospinal fluid leaks in transsphenoidal surgery. Neurosurgery 60:295-304, 2007

19. Fahlbusch R, Schott W: Pterional surgery of meningiomas of the tuberculum sellae and planum sphenoidale: surgical results with special consideration of ophthalmological and endocrinological outcomes. J Neurosurg 96:235-243, 2002

20. Fatemi N, Dusick JR, de Paiva Neto MA, Malkasian D, Kelly DF: Endonasal versus supra-orbital keyhole removal of craniopharyngiomas and tuberculum sellae meningiomas. Neurosurgery 62:325-330, 2008

21. Goel A, Muzumdar D, Desai KI: Tuberculum sellae meningioma: a report on management on the basis of a surgical experience with 70 patients. Neurosurgery 51:1358-1364, 2002

22. Hadad G, Bassagasteguy L, Carrau RL, Mataza JC, Kassam A, Snyderman $\mathrm{CH}$, et al: A novel reconstructive technique after endoscopic expanded endonasal approaches: vascular pedicle nasoseptal flap. Laryngoscope 116:1882-1886, 2006

23. Jane JA Jr, Dumont AS, Vance ML, Laws ER: The transsphenoidal transtuberculum sellae approach for suprasellar meningiomas. Semin Neurosurg 14:211-217, 2003

24. Jho HD: Endoscopic transsphenoidal surgery. J Neurooncol 54:187-195, 2001

25. Jho HD, Ha HG: Endoscopic endonasal skull base surgery: part 1-the midline anterior fossa skull base. Minim Invasive Neurosurg 47:1-8, 2004

26. Kassam A, Carrau RL, Snyderman CH, Gardner P, Mintz A: Evolution of reconstructive techniques following endoscopic expanded endonasal approaches. Neurosurg Focus 19(1):E8, 2005

27. Kassam A, Snyderman CH, Mintz A, Gardner P, Carrau RL: Expanded endonasal approach: the rostrocaudal axis. Part I. 


\section{E. de Divitiis et al.}

Crista galli to the sella turcica. Neurosurg Focus 19(1):E3, 2005

28. Kassam A, Thomas AJ, Snyderman C, Carrau R, Gardner P, Mintz A, et al: Fully endoscopic expanded endonasal approach treating skull base lesions in pediatric patients. J Neurosurg 106:75-86, 2007

29. Kassam AB, Snyderman C, Carrau RL: Expanded endonasal approach: an evolving paradigm to the ventral skull base. Skull Base 14 (1 Suppl):23, 2004 (Abstract)

30. Kim J, Choe I, Bak K, Kim C, Kim N, Jang Y: Transsphenoidal supradiaphragmatic intradural approach: technical note. Minim Invasive Neurosurg 43:33-37, 2000

31. Kitano M, Taneda M: Extended transsphenoidal approach with submucosal posterior ethmoidectomy for parasellar tumors. Technical note. J Neurosurg 94:999-1004, 2001

32. Kitano M, Taneda M, Nakao Y: Postoperative improvement in visual function in patients with tuberculum sellae meningiomas: results of the extended transsphenoidal and transcranial approaches. J Neurosurg 107:337-346, 2007

33. Laufer I, Anand VK, Schwartz TH: Endoscopic, endonasal extended transsphenoidal, transplanum transtuberculum approach for resection of suprasellar lesions. J Neurosurg 106:400-406, 2007

34. Locatelli D, Rampa F, Acchiardi I, Bignami M, De Bernardi F, Castelnuovo P: Endoscopic endonasal approaches for repair of cerebrospinal fluid leaks: nine-year experience. Neurosurgery 58:ONS-246-256; discussiom ONS-256-247, 2006

35. Margalit NS, Lesser JB, Moche J, Sen C: Meningiomas involving the optic nerve: technical aspects and outcomes for a series of 50 patients. Neurosurgery 53:523-532, 2003

36. Mathiesen T: Comment on Nakamura M, Struck M, Roser F, et al: Olfactory groove meningiomas: clinical outcome and recurrence rates after tumor removal through the frontolateral and bifrontal approach. Neurosurgery 60:844-852, 2007

37. Mathiesen T, Kihlstrom L: Visual outcome of tuberculum sellae meningiomas after extradural optic nerve decompression. Neurosurgery 59:570-576, 2006

38. Nakamura M, Roser F, Struck M, Vorkapic P, Samii M: Tuberculum sellae meningiomas: clinical outcome considering different surgical approa hes. Neurosurgery 59:1019-1029, 2006

39. Nakamura M, Struck M, Roser F, Vorkapic P, Samii M: Olfactory groove meningiomas: clinical outcome and recurrence rates after tumor removal through the frontolateral and bifrontal approach. Neurosurgery 60:844-852, 2007

40. Nozaki K, Kikuta K, Takagi Y, Mineharu Y, Takahashi JA, Hashimoto N: Effect of early optic canal unroofing on the outcome of visual functions in surgery for meningiomas of the tuberculum sellae and planum sphenoidale. Neurosurgery 62:839-846, 2008

41. Otani N, Muroi C, Yano H, Khan N, Pangalu A, Yonekawa Y: Surgical management of tuberculum sellae meningioma: role of selective extradural anterior clinoidectomy. Br J Neurosurg 20:129-138, 2006

42. Pamir MN, Ozduman K, Belirgen M, Kilic T, Ozek MM: Outcome determinants of pterional surgery for tuberculum sellae meningiomas. Acta Neurochir (Wien) 147:1121-1130, 2005

43. Park CK, Jung HW, Yang SY, Seol HJ, Paek SH, Kim DG: Surgically treated tuberculum sellae and diaphragm sellae meningiomas: the importance of short-term visual outcome. Neurosurgery 59:238-243, 2006

44. Raco A, Bristot R, Domenicucci M, Cantore G: Meningiomas of the tuberculum sellae. Our experience in 69 cases surgically treated between 1973 and 1993. J Neurosurg Sci 43:253-262, 1999

45. Rosenstein J, Symon L: Surgical management of suprasellar meningioma. Part 2: Prognosis for visual function following craniotomy. J Neurosurg 61:642-648, 1984

46. Schick U, Hassler W: Surgical management of tuberculum sellae meningiomas: involvement of the optic canal and visual outcome. J Neurol Neurosurg Psychiatry 76:977-983, 2005

47. Schwartz TH, Fraser JF, Brown S, Tabaee A, Kacker A, Anand VK: Endoscopic cranial base surgery: classification of operative approaches. Neurosurgery 62:991-1005, 2008

48. Yașargil MG: Meningiomas, in Yașargil MG (ed): Microneurosurgery, Vol 4B. Stuttgart-New York: Georg Thieme Verlag, 1996, pp 134-165

Manuscript submitted July 31, 2008.

Accepted September 23, 2008.

Address correspondence to: Enrico de Divitiis, M.D., Department of Neurological Sciences, Division of Neurosurgery, Università degli Studi di Napoli Federico II, Via Sergio Pansini, 580131 Naples, Italy.email: dediviti@unina.it. 